\title{
Understanding the Experience of Discovering a Kindred Spirit Connection: A Phenomenological Study
}

\author{
Linda Finlay, PhD, Faculty of Social Sciences, the Open University, Milton Keynes, \\ UK \\ Email: L.H.Finlay@open.ac.uk \\ Virginia Eatough, PhD, Department of Psychological Sciences, Birkbeck University \\ of London, London, UK \\ Email: v.eatough@bbk.ac.uk
}

\section{Abstract}

Preliminary existential-hermeneutic phenomenological analysis of data based on 24 protocols, and our own reflexive discussion, reveals how "kindred spirit connections" manifest in myriad elusive, evocative ways. These special connections are experienced variously from briefly felt moments of friendship to enduringly profound body-soul love connections. This paper explicates five intertwined dimensions: shared bonding; the mutual exchange and affirmation of fellowship; the destined meeting or relationship; immediate bodily-felt attraction; and the pervasive presence of love. A wide ranging literature around the theme of love is outlined and the concept of kindred spirit is briefly applied to the psychotherapy practice context.

\section{Introduction}

\section{Not Love Perhaps}

...A need, at times, to be together and talk, And then the finding we can walk More firmly through dark narrow places, And meet more easily nightmare faces; A need to reach out, sometimes, hand to hand, And then find Earth less like an alien land;

A need for alliance to defeat

The whisperers at the corner of the street...

(A.S.J. Tessimond)

This paper was borne out of reflections on an especially heart-warming and intellectually stimulating Human Sciences Research Conference in 2008. We (Linda and Virginia) have attended many of these conferences and noted the deep-rooted and 
meaningful connections which we experienced at these times, both with each other and other people. We found ourselves using the phrase "kindred spirit" to describe our feelings of being understood and accepted by others, alongside the awareness of shared interests and passions.

We became curious - what was this experience? There were elements that seemed akin to falling in love but this characterization, itself not easily understood, does not fully capture the phenomenon. Does everyone have this experience and name it thus? Can we describe it? How could/should such experiences be fostered? How might such experiences be relevant in our professional practice?

Out of such wonder-ing, our question emerged: What is the experience of discovering a kindred spirit connection? We embarked on this journey in a spirit of openness and curiosity. We did not want to encumber ourselves with existing theoretical ideas from academic disciplines, literature, art and so on. We aimed to approach the phenomenon with fresh eyes, to put aside our presuppositions while recognizing that they are never completely out of play. To this end, we did not examine extant literature until analysis of the descriptions we collected was complete. Thus, this paper departs from typical formats: We leave discussing relevant literature until the latter part of the paper where we also suggest some professional practice applications.

\section{Our Methodological Approach}

[Phenomenological description] must stick close to experience, and yet not limit itself to the empirical but restore to each experience the ontological cipher which marks it internally. (Merleau-Ponty, 1960/1964, p.157)

Our aim was to capture the kindred spirit phenomenon in the embodied, relational way as it is concretely lived. Our focus was on that which "appears meaningfully to consciousness in its qualitative, flowing given-ness; not an objective world 'out there’, but a humanly relational world” (Todres, Galvin, \& Dahlberg, 2007, p. 55). We were guided by existential-hermeneutic phenomenological principles (Valle \& Halling, 1989; van Manen, 1990).

We wanted to capture as much richness and complexity as possible. We prized description above any kind of a-priori explanation or theorizing: we were not asking why a person might have said something, rather what might be being revealed (Finlay, 2011). Hermeneutic-phenomenology prioritizes rich description but it also acknowledges the inevitable role of interpretation (van Manen, 1990). We attended to contextual meanings, including our knowledge of the participants' situations and how our own subjectivity as researchers was inextricably intertwined with interpretations made (Churchill, 2007). This has been likened to a dance:

The researcher engages a solo waltz... moving in and out of (prereflective) experience and reflection as the researcher engages multiple meanings emerging from the data. Different interpretations are tried out like dance steps. Eventually the researcher settles on particular 
meanings revealing possibilities that may excite, inform or point the way to future research. (Finlay, 2006, p. 1)

Only after developing textured experience-near descriptions, did we attempt to thematize these through carefully chosen language, refracted through a variety of lenses - philosophical, theoretical, literary and reflexive (Finlay, 2011). We acknowledged our own lived experience of kindred spirit connections and challenged each other to go beyond these to discover different understandings.

Finally, we adopted as our starting point an idiographic approach, making no assumptions about a shared reality ranging across different individuals. We also accepted participants' expressions without moral judgment, assuming them to reflect their perceptions of their experience. Applying a phenomenological attitude (Finlay, 2008), we attempted to bracket our presuppositions in order to attend, genuinely and actively, to our participant's experience. At the same time, we had as a horizon an awareness of the 5000+ years of history where "poets, writers, and troubadours" have struggled to sing the "delights and sufferings of love” (Hatfield, Bensman, \& Rapson, 2012, p.143).

\section{Participants}

We separately approached friends, colleagues and friends of friends, each of whom was promised complete anonymity. The final number of participants (24) represented a small and relatively culturally homogenous group of Europeans and North Americans.

Each participant provided a written description (protocol) of an experience of "discovering a kindred spirit connection." How this was done was left to the individual. Some wrote a page; others wrote several. Some wrote a chronology of their relationship; others focused on the specific moment of discovering a kindred connection.

It was harder than we expected to find people who felt they had experienced kindred spirit connections. Of those who had, several refused the invitation to share their story publically. They just could not write about it: the experience was too intense, "too sensitive," "too personal," "too hard to put into words." It is significant that this topic posed such challenges. Of those who agreed to contribute, however, several spoke of enjoying the process of writing and the opportunity to share - and in some sense to re-live - their experience.

We were challenged - overwhelmed - by the individual character of each account. At first glance each seemed to have little relationship to the next. It became clear that this diversity reflected the unique understandings of each individual participant, and that, for most individuals, the experience resonated powerfully and held great meaning. All the stories were touching, often poignant. Many were quite beautiful and elicited our tears.

The fact that we, as researchers, knew some of the participants is more than likely to have influenced the data we obtained. Mutual trust already in place with some 
meant they felt freer to provide more personal details. Others were more cautious, perhaps aware of the wider, more public implications of research.

\section{Analysis}

Analysis involved us working in a fluid, dynamic manner, treating our understandings as emergent. The analytic process proved a messy, uneven one, involving imaginative leaps of intuition as well as the systematic working through of many iterative versions over time. As with all phenomenological analysis, our focus was on descriptively revealing both explicit and hidden meanings. This involved us dwelling with the data, examining it and then progressively deepening understandings as meanings came to light.

We initially drew on various structured guidelines for phenomenological analysis (such as considering approaches to: eidetic analysis found in the descriptive phenomenology of Giorgi, 1985 and Wertz, 1983; and thematic analysis found in the interpretative phenomenological analysis of Smith, Flowers \& Larkin, 2009). However, we settled on a more general interpretive approach.

We worked individually at first, undertaking repeated, systematic readings of each protocol. This involved a process of empathic immersion through which we aimed to become wrapped-up in the participants' descriptions. Next, we each documented our emergent understandings for each protocol at a thematic level while aiming to be provisional, open and cautious. A third stage involved us coming together in discussion to share, reflect and refine our early understandings. Thus, a sense of what it means to have a kindred spirit connection began to take shape. We spent many hours discussing how best to language the different themes in a way which would encapsulate both the idiographic and shared elements of the experience.

The process of analyzing the accounts became, for both of us, an embodied, reflexive lived experience in itself rather than simply a cognitive, intellectual exercise. We found ourselves sensing, moving, empathizing, responding and resonating with our whole body-selves, sometimes almost re-living and re-embodying what was said. We sought out those parts which resonated for us as individuals, often when something particularly significant, interesting, poignant or paradoxical was being said (Finlay, 2011).

Out of the analysis emerged the discovery that a kindred spirit connection seems to involve, to varying degrees, dimensions of: i. Bonding, ii. Fellowship, iii. Destiny, iv. Chemistry, and v. Love. In addition, we identified facets within these which speak to the myriad ways the dimensions can manifest themselves in the experience of the individual. For example, one participant identified a fleeting handshake as a significant moment of connection, another, a tragic love story which extended over many pages. It felt important to honor these different types of experience. 


\section{Findings}

Our analysis suggests that, for our participants at least, experiencing a kindred spirit connection can take many forms, happening in many different relationships and contexts, and that the experience cuts across age and gender. Nonetheless, within this multiplicity, experiencing a kindred spirit connection seems to manifest itself in one of the following ways: close, shared bonding; the mutual exchange and affirmation of fellowship; the destined meeting or relationship; immediate bodily-felt attraction; and the pervasive presence of love.

We offer a brief analytic description of these five dimensions which form, at least in part, the meaning of the kindred spirit connection. We envisage them as fluid and blended; some might be wholly absent from an individual experience whilst for others, all the dimensions are present to varying degrees. The facets contained within each dimension are then identified using italics. We illustrate our analysis with excerpts taken from participants' protocols which speak to the intensity participants felt and the open receptivity within which they sought to understand their own experience.

\section{Bonding: Close Meaningful Friendships}

Bonding involves an experience of deep, meaningful friendship - a close sense of sister/brotherhood. There is an easy, trusting, meeting of minds; a safe, affirming feeling of being understood; a freeing delight in simply being-with the other. There is a sense of deepening and consolidation of the connection because of the sheer effortlessness of being together. This dimension has a quality of richness and fullness embracing facets such as "solidarity," "meshing," "enrichment," and a "delighting in the other."

With "solidarity" comes a commitment to reciprocity and mutual exchange and there is a sense of loyalty and of siding-with the other against all adversity. With "meshing" comes a sense of commonality - a fit - not only of shared interests, views, passions but of existential issues also. There is a meeting of minds and an acceptance of idiosyncratic peculiarities; a recognition of self-in-the-other and of shared history.

For one participant, the connection emerged from recognizing shared pain and sorrow resulting from marital breakdown. They had been colleagues who on meeting up again connected through the shared experience:

The reciprocation, the talking and listening and feeling very directly each other's sadness and so forth, was very easy and happened so quickly - leading to feeling very connected. And I think the most striking thing was the direct feeling of things that she was describing the anger about things that she had been put through, the sadness (and I remember tears from a number of times we spent together)...that I felt very directly, probably because of the similarities of life events that we had both been experiencing...I also remember the feeling of "siding with" her against the causes of all the unhappiness - as if there were 
one set of people in the world that caused unhappiness, and one set that were on the receiving end, and that we were on the same team. (\#17)

"Enrichment" involves validation, affirmation and gaining from the relationship. To be with the other is to feel enabled, healed, nurtured by the other's recognition, admiration and acceptance. There is a feeling of being understood and no longer alone. This enrichment is expressed through a story of young love, a love which is all consuming for a time and leaves one desolate when it dies:

I thought that my whole world was over and that I would never love again when she appeared, that warm smile with a cuppa...we had smiled and said hello on many occasions, but I didn't really know much about her. This sounds like a love story doesn't it, and in a way I guess it is. That evening I went to her house for a drink and poured my heart out to her... [She] took me under her wing that night until I put myself back together again. She is my rock when I need it and the one that will always pick me up, brush me down and put me back together. She to me will always be my kindred spirit. (\#14)

With a "flowing easiness," there is a comfort and ease and at-homeness in the relationship; the connection is one of warmth and trust. It feels safe to reveal and to disclose in this threat-free atmosphere. The image evoked is of a soft blanket enveloping one's being.

"Delighting in the other," involves a taking of pleasure in the other's company enjoying and admiring the other in a non- superficial way, e.g. one participant described getting to know her "new friend":

It felt like that afternoon we'd shared loads with each other and that we just seemed to connect. Although there was an age difference between us, we seemed to view the world in similar ways and I found her company very easy - she's easy to talk to and I felt really comfortable talking about quite personal things. (\#8)

Here, there is a sense of deepening and consolidation of the connection because of the sheer effortlessness of being together.

\section{Fellowship: Affirming Meeting of Minds}

Bonding seems to involve longstanding, enduring friendship or the possibility of it. In contrast, fellowship relationships may involve a single encounter or a fleeting contact. There is a moment in which minds meet, and the context is often more public than that described above.

The initial meeting tends to occur by chance, often in a context of uncertainty, challenge or tension: a tense Union meeting, going into a room as a stranger, or giving a talk where one's view is unpopular. One feels alone, different, isolated. Suddenly, an unexpected, and perhaps rare, connection is discovered. "I certainly felt a sharing 
of opinion...a warmth of feeling with him... in a general historical situation of considerable tension, ambiguity and worry” (\#7).

There is mutual liking and attraction, a sense of warmth; a sympathetic cerebral vibration and an affirming "meeting of minds" or sameness (perhaps through a shared sense of humour or a shared belief). Although the other may be very different (perhaps older or senior in rank) there is a feeling of being accepted and appreciated. There is a natural seamlessness, balance and harmony; a certain "confluence and commonality." "He seemed to understand where I was coming from ... Much of what he said and the views he held struck a chord with me and I felt that on a fundamental level we understood each other" (\#20).

This feeling of knowing the other in a deep-rooted way despite the oftenmomentary nature of the encounter was echoed in several stories.

"It was as though we had been travelling the same journey in parallel, never meeting but experiencing the same frustrations, excitement and challenges. We had shared one email correspondence and yet I felt as though I had known him forever” (\#16).

Fellowship also often involves the surprise discovery of an "instant affinity":

When you turned to read my poem,

I felt your easy presence come to tighter focus;

distilled and pressing through arteries and nerves, dense as mercury.

I felt the weight bear down, not knowing its strength, like when I held a car from rolling and risked its crush.

I braced to swing up and take the load;

to accept compression but still to hold my own;

and, as we talked, I felt a tilt of levelling, and joy (\#4)

The friendship described poetically above was to continue for more than ten years, sustained by regular monthly cafe meetings.

\section{Destiny: Meeting a Soulmate}

At last everything falls into place,

The jigsaw is complete.

...The balm of your existence soothes my wounds,

Our beings interlock with one another.

Alone no longer,

I feel your magnetism stronger than ever before.

Body and soul engage,

Beings merge into a single entity.

Your warmth penetrates my flesh,

Finally we are whole. (\#9)

This poem captures a key quality of the destiny dimension in that it speaks to the element of fate that can attend the experience of a kindred connection. One's way of 
being in the world shifts profoundly. Kismet is evoked with participants believing and feeling that the relationship is simply meant to be; they are souls on a journey destined to meet; they feel an "inexorable pull" towards the other. This pull is akin to that of a magnet with a corresponding sense of things having to have been in place otherwise it might not have happened. The union seems to have a spiritual dimension with participants experiencing a sense of recognition or instantaneous knowledge of who and what the other person is. As one participant exclaimed: "I knew I knew this man! I wanted to be with this man for the rest of this life on Earth!” (\#1).

The Other is seen as a "nurturing presence" and the connection is experienced as encouraging, comforting and accepting. The Other is teacher, healer, therapist, guide, friend, lover and guardian in one. They are a safe haven, providing a sense of significance and embodying all that is desired and valued.

Alternatively, there can be an experience of "exultation with nature," bringing heightened awareness of the physical world and a greater sense of communion with it through the growth-full connection with the other. The experienced connection is grounded in nature and bodily sensuality:

I was so grateful to be able to commune with the earth and its bounty, the sun, and my new friends. I delighted in the feeling of the silky, warm soil between my toes, as I walked the rows of plants, feeling the sun's warmth on my bare legs and feet. I loved tasting the sunshine in a vine-ripened tomato as I popped it into my mouth, the delicious fruit bursting inside, juice running down my chin as I bit down happily on its sun-warmed skin. (\#1)

For some participants, there is a sense of "union with the one and only," a joining at multiple levels: mind, body and soul. Feelings of bodily dissolution, purity, exultation and joy prevail:

The quality and nature of our "togetherness" that evening is really beyond words to capture....the depth of respect, acceptance, wisdom....and love... our meeting truly beautiful, magical and wondrous....... blessing which we may understand as the meeting of "kindred spirits"... the meeting of souls...? (\#11)

Lastly, there is a sense of "Other-worldliness" about the connection. The world becomes an enchanted, magical place, full of mystery. The world and the union are bigger than oneself and life takes on the patina of an idyll whilst symbolic signs point to the inevitability of the connection. One participant described this other-worldliness in a story about her dog, Higgins, who uncharacteristically ran off to greet a stranger. She believed this was the result of "a higher power" (\#19). The stranger eventually became her life partner.

\section{Chemistry: Bodily-felt Affinity, Attraction and Eros}

This erotic dimension seems to us to be of a slightly different order than the others and was only present in a small number of descriptions. More than any of the other 
dimensions it is explicitly rooted in the body, simmering away as base, primordial, bodily "lust." Infused with passion, emotions feel overwhelming and sometimes there is a thrilling sense of danger - risky, scary but exciting. The connection is experienced as "intoxication" associated with headiness and uninhibited wildness. There is also a sense of an "energising" cocktail involving magnetic attraction, experienced as a physical force. Connections spark with electricity. Chemistry simply fizzes.

Writing about a man she had encountered through an online dating agency, one participant described an instant physical attraction and connection which then developed over the course of the meeting, leaving a "buzz of energy":

I leant forward to kiss him on the cheek and this time found myself kissing him fully on the lips. It is hard to describe what happened in that moment - electricity seems such a cliché - but that is the closest I can get to find the right word. A buzz of energy going to the top of my head and down, down, down... Thrilling and startling all at once...I felt very nervous. Not about him, but about meeting someone with whom I felt this strongly. I knew this would not be a casual affair. It could not possibly be casual. (\#5)

For another, connecting with a kindred spirit meant an "instantaneous connection" be it sexual, creative or social in form:

The reaction, the recognition, the feeling, preceded any conscious knowledge of what the other was like. When the connection happens, I feel as though some sort of energy field is rippling or extending out, like hairs standing up on my arm, or a warmth, except it is like a colour too. I feel like a flower stamen revolving on a stalk on the sun. The recognition has nothing to do with conscious information or logic...it feels like a non-verbal compatibility of energies. Not even prolonged eye contact is necessary for the recognition to occur and in fact might initially feel a bit too intense. It’s very strong. (\#6)

This participant's account was unusual in that the account was more abstract and conceptual than the others. Nevertheless, as with the other descriptions, the body is foregrounded, with the power of the connection appearing to rampage through it.

\section{Love: Romance, Sex, Friendship and Agape}

We found the love dimension the most diffuse and hard to pin down. Throughout our project (from early discussion to analysis) its presence was continually felt as an everpresent horizon. Eventually we realized that, in a variety of ways, love leaked into and touched all the other dimensions. One feels love for a lover and this love is likely to have elements of bonding, chemistry and destiny within it. Love for a family member or friend is characterized by bonding and fellowship. 
Not surprisingly, our participants struggled to capture what love meant to them. One participant - not literary-minded nor of an academic background - tries to do this by writing from the heart:

And I felt so "whole"...I somehow, in the briefest of times, had said a few words about so many important and strongly protected aspects of myself... and each time I spoke I felt heard and met and honoured by S....and that she embraced me further and further in love, as I did her. And I so enjoyed my sense of myself growing fuller in her presence...And in our sharing there was a sense of profound togetherness, perhaps like two figures, side by side, looking into a deep wondrous pool of water, and seeing their reflections merging in the ripples into one...each knowing they are separate, but at the same time feeling profound togetherness in a place beyond...for me this was very beautiful...very rare...very special... I felt somehow a "perfection" in our meeting....nothing jarring, no anxieties, no "partlys" or "nearlys"...a very special quality to our meeting...something quite outstanding...like a perfect fit. And I felt so fully alive. (\#11)

This description draws attention to how some forms of love are about merging, unity and perfection, however momentarily. For other participants there is a sense of the heart being captured or "hooked." The other stands out from the crowd and the "heart flips” giving rise to a sense of aliveness. The world feels brighter, more beautiful:

I felt my heart flip when he smiled at me. To be fair he was probably smiling at everyone that way. But it felt special as if to me alone; as if my soul was being warmed. (\#10)

Here, we suggest love means "flowering in the presence of the other" so that one feels special and warmed by the other as a flower is touched by sun and rain. As this participant went on to say: "Somehow, I feel good when he is in the room with me" (\#10). It seems that the simple presence of the kindred spirit can be enough to enhance one's very being.

\section{Discussion}

We view this study as exploratory; our analytic findings preliminary. It raises more questions than it answers which we feel is no bad thing at this stage. It is possible we are actually dealing with multiple phenomena. The dimensions we have identified need to be explored in their own right in order to tease out if they share some core quality or characteristic. Also, we wonder if at bottom, these kindred spirit connections are all about love; that love is a unifying thread which weaves the experience together. 


\section{Examining the Literature}

On turning to the literature, we realized that this experience had received little attention, although the phrase "kindred spirit" is invoked often with little clarification and numerous assumptions made. For example, it is sometimes used in psychological research when the focus is the factors involved for romantic relationships to succeed (e.g. Murray, Holmes, Bellavia, Griffin \& Dolderman, 2002). Here, a kindred spirit is defined as "someone who understands them [the significant other] and shares their experiences” (p. 563).

Similarly, in literary sources, we found reference to the kindred spirit as the longed-for ideal friend identified, for instance, in the letters of those "restless" nineteenth century women who yearned for fulfillment and freedom from male domination (Taylor \& Lasch, 1963):

Life is short, and kindred spirits are few, the chances of their meeting are fewer still. And poor human nature has so many jarring strings, that, after all, friendship is something more to be worshipped as an ideal good, than a real, and possible thing, something that may be, rather than something that is. (Case, 1839, cited in Taylor \& Lasch, 1963)

Elsewhere, the idea of a kindred spirit is appealed to as a way to illustrate the closeness and similarity of the artistic relationship between the poet William Cullen Bryant and the poet Thomas Cole (Ringe, 1954). These notions of similarity, sharedness, friendship are also found in philosophical and theoretical understandings of love - a topic of research which has dramatically broadened and deepened more recently to emphasize its multi-faceted appearance (Hatfield et al., 2012). It is to these we now turn in the hope of further shedding light on this hard-to-grasp phenomenon of kindred spirit connection.

In the classical literature, Socrates was perhaps one of the first to identify several forms of love: family, affectionate (storge); friendship (philia), romantic, desiring (eros) and unconditional, spiritual love (agape). Aristotle enlarged on these categories including distinguishing between philia friendships of utility, friendships of pleasure and friendships of the good (i.e. relationships that are authentic, mutual, cooperative).

Similarly, the belief that love has many faces is evident in contemporary psychological research (Fehr, 1994). Hendrick and Hendrick (1993) note the evidence that friendship love is described as being an important aspect of romantic relationships more frequently than with passionate love. Both Sternberg's (1986, 1988) triangular theory of love and Lee's (1988) love story card-sort conceive of different love styles which people take up and live out in their relationships. The triangular theory of love comprises of three factors, passion, commitment and intimacy, the different combinations of which gave rise to different forms of love such as consummate love which contains all three factors and infatuation which contains only passion. Lee uses the analogy of the colour wheel to identify primary and secondary love styles, the three primary ones being eros (passionate), storge (companionate), ludus (game-playing) with the secondary ones comprising mania 
(possessive), pragma (logical) and agape (selfless). Although many of these kinds of love can be discerned in participants' descriptions of their kindred spirit connection, their experiences are more than what is offered by them.

In the existential literature, Rolly May (1969) proposed:

- Autistic love - which is focused on "me" and expressed as Libido or Eros.

- Empathetic love - which is focused on "you" and expressed as Philios or Agape.

- Integral love - which is focused on caring about the "us" and blending the previous versions into an integrated whole. (See table 1)

\begin{tabular}{|c|c|c|}
\hline $\begin{array}{c}\text { Type of } \\
\text { Literature }\end{array}$ & Categories of Love & $\begin{array}{c}\text { Link to } \\
\text { Kindred Spirit } \\
\text { dimensions } \\
\end{array}$ \\
\hline $\begin{array}{l}\text { Classical } \\
\text { (e.g.Socrates/ } \\
\text { Aristotle) }\end{array}$ & $\begin{array}{ll}\text { - } & \text { Storge (family affection) } \\
\text { - } & \text { Eros (desiring) } \\
\text { - } & \text { Agape (spiritual, love of man) } \\
\text { - } & \text { Philia (friendships of utility, } \\
& \text { pleasure and good) }\end{array}$ & $\begin{array}{ll}\text { - } & \text { Love \& Bonding } \\
\text { - } & \text { Love \& Chemistry } \\
\text { - } & \text { Love \& Destiny } \\
\text { - } & \text { Love, Bonding \& } \\
& \text { Fellowship }\end{array}$ \\
\hline $\begin{array}{l}\text { Existential } \\
\text { (e.g. May) }\end{array}$ & $\begin{array}{l}\text { - Autistic Love expressed as } \\
\text { libido/eros } \\
\text { - Empathetic Love expressed as } \\
\text { phila or agape } \\
\text { - Integral Love integrating all }\end{array}$ & $\begin{array}{l}\text { - } \text { Chemistry } \\
\text { - } \quad \text { Love, Fellowship \& } \\
\text { Bonding } \\
\text { - Love, Destiny, } \\
\text { Bonding, Chemistry \& } \\
\text { Fellowship }\end{array}$ \\
\hline $\begin{array}{l}\text { Literary (e.g } \\
\text { Lewis) }\end{array}$ & $\begin{array}{ll}\text { - } & \text { Character friendship } \\
\text { - } & \text { Deep friendship } \\
\text { - } & \text { Romantic/passionate } \\
& \text { relationship }\end{array}$ & $\begin{array}{ll}\text { - } & \text { Fellowship } \\
\text { - } & \text { Bonding } \\
\text { - } & \text { Love \& Chemistry }\end{array}$ \\
\hline
\end{tabular}

Table 1: Comparison of key types of love mapped on our own Kindred Spirit dimensions

As Sleeth (2010) acknowledges in his developmental analysis for fostering love in clinical practice, integral love is more complicated and takes the form of Buber's IThou relating where the boundary between self and other melts away. Such a state is perhaps what Rogers (1980, cited in Sleeth, 2010, p. 489) meant when he said "it seems that my inner spirit has reached out and touched the inner spirit of the other."

C. S. Lewis (1960) engaged the four classical Greek loves emphasizing the Christian charity virtues of agape and the longing for emotional connection found with eros. He also distinguished other forms of friendship. He separately described "character friendships" such as two acquaintances in a group encountering a moment where each is stunned to find the other shares the same kind of thoughts, interests and 
views as themselves. A deep friendship is forged upon the strength of shared visions or enthusiasms which sets the two apart from the group and kindred spirit connection is born (Lewis, 1960, p. 79). According to Lewis, a kindred spirit friendship is not the same as experiencing a kindred spirit connection in a romantic relationship. The latter involves "naked bodies" whereas the former entails "naked personalities" and there is nothing to "quicken the pulse" (Lewis, 1960, p. 79).

However, the idea of different styles of loving implies some rigidity and, as already noted, they do not appear to strike at the heart of our participants' experiences in which both different forms of loving are present but overlaid by a quality of moreness. Other commentators have found the boundary between friendship and romantic love, for instance, to be more blurred. Kierkegaard regards both eros and philia as "involuntary feelings ignited by the beloved's physical, psychological qualities" (Reeves, 2005, p.4). These powerful encompassing feelings are echoed by Montaigne in a letter to his friend Etienne la Boetie:

Take me and all I have, give me but your love, my dear friend. Tuesday is longed for by me and nights and days move to a tedious pace till I am near you. (Vernon, 2005, p. 29)

Montaigne's absorption in and overwhelming desire to be with his friend is reminiscent of romantic love suggesting degrees rather than any absolute difference.

Our analysis shows something of the complexity and range of the kindred spirit connection with its subtle merging and blurring of body, soul and mind which cannot be accounted for by the notion of discretely separate types of love as discussed above. Yet, we are left with something of a conundrum - is the experience of connecting with a kindred spirit best understood as a single phenomenon? To what extent are we engaged in semantic play where the meanings of this powerful experience can only be partially articulated:

This whole experience is carried by the body and is "more" than the heat, "more" than who you were with, "more" than other personal times and places that resonate with the hot summer's night. The experiential sense of all of this can be thematized and languaged, and meaningful aspects separated out from this "preseparated multiplicity." (Todres, 2007, p. 21)

At this point, we suggest that the layered, often mysterious nature of the kindred spirit experience, with its intriguing configuration of overlapping dimensions, should be accepted - even celebrated. The aim is to move towards a more holistic understanding which recognizes the intertwining of body-mind-soul as part of being-with an Other in a special relationship. We suggest that the reality of the kindred spirit connection is greater than the shared sum of parts and that future research should seek to understand further the myriad of forms through which it manifests itself.

Further illumination, we suggest, might also be found in phenomenological theory, though space does not permit elaboration. For instance, there is the relevance of aspects of the "peak experience" (Maslow, 1968) such as fulfillment, significance and spirituality and even the concept of "flow" (Csikszentmihalyi, 1990). More 
tentatively, the quality of "at-homeness" (Heidegger, 1927/1962) with an Other might be one which threads through each dimension. Other relevant phenomenological philosophy includes: Buber's (1937/1958) focus on our relational ontological grounding; Levinas' (1961/1969) notion of the paradoxical nature of love and how the loved one is always infinitely more than we can ever know; and Sartre's (1943/1969) view that love is an "impossible project" wherein we strive to attain totality of being through the use of another.

\section{Revisiting Dimensions of Kindred Spirit Connection}

Figure 1 illustrates the multifaceted nature of the kindred spirit connection which encompasses briefly felt moments of friendship to enduringly profound body-soul love connections. We have attempted to show where the different dimensions blur and no single dimension stands alone. These various dimensions appear to exist as latent possibilities lingering on the horizon of the encounter, awaiting their chance to become figural.

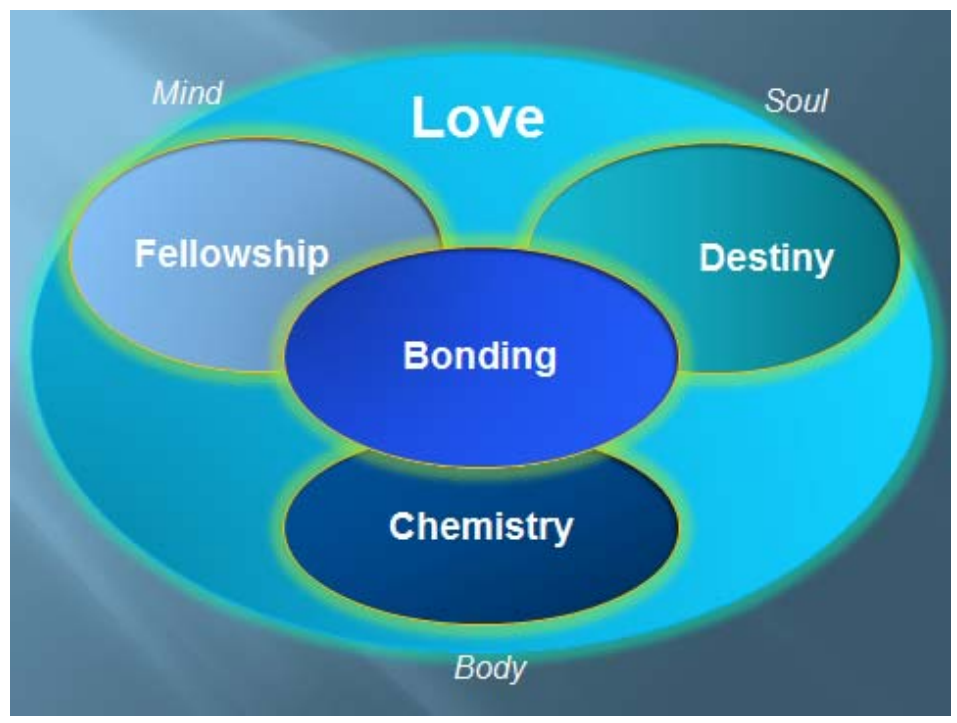

Figure 1: Proposed dimensions of the kindred spirit connection

As Figure 1 indicates, we suggest that some form of love palpably infuses each of the other four dimensions. Love also provides a link enabling each dimension to feel something of bodily eros and both mind and destiny connections.

Love (whether it be fraternal, affiliating, romantic or of deep friendship) seems to have a fundamental place in our existence...love seems to manifest to the human existence as a condition of necessity. (Correia, 2008, p. 268)

Likewise, bonding is closely implicated in fellowship, destiny and chemistry. This is not surprising given that bonding, for many of our participants at least, meant experiencing both closeness and love through deeply significant friendship and intense bodily felt attraction. 
So deeply is love rooted in human nature, so essentially does it belong to a human being...Erotic love is undeniably life's most beautiful happiness and friendship the greatest temporal good. (Kierkegaard, 1847/1995, p. 157)

Our analysis suggests that chemistry is separate from fellowship and destiny. Chemistry, as a potent bodily-felt dimension is erotically present in a loving relationship or one based on close bonding but its passion seems too powerful for the meeting of minds which characterizes the fellowship dimension and the magical other-worldliness of destiny.

In the world of passion, the body is a vessel, a sounding board through which reverberates the turmoil from the depth and the surrounding. We feel the turmoil of all flesh in our flesh. The sight of bouncing breasts or of swaying hips can spread like panic through the entire body. In the world of passion, we are communing vessels in which the upheaval collects itself. (Jager, 1989, p. 224)

With fellowship and destiny, the body is not foregrounded (though is, of course, still ever-present); rather the spiritual and the meeting of minds predominates. Thus, it seems that each dimension represents different manifestations of the intertwining of body-soul-mind.

\section{Evaluation and Relevance to Professional Practice}

Our idiographic approach has revealed the value of attending to individual meaning rather than assuming too quickly a more general understanding. Analysis of the descriptions strongly suggests that, at this early stage, any attempt to present the experience of connecting with a kindred spirit as a single phenomenon is ill-advised. Further exploration of the five dimensions is called for. We offer them as a starting point acknowledging that they are tentative, partial and emergent - work in progress. Nevertheless, we are reassured that the qualities of these dimensions echo the wider literature on love. Our task now is to continue to work idiographically within the context of each dimension in order to deepen understanding of the particular qualities each holds.

Our research was limited further by the relatively culturally-homogenous group of participants. All our participants were of either European or North American origin and the meaning of a kindred spirit connection might be something very different for people from more interdependent and collectivistic cultures. However, as Hatfield et al. (2012, p. 155) note, "passionate love" appears to be a "cultural universal" though there may be cultural variability particularly when religious or political prohibitions dampen passion. Critically exploring the intersection of personal and social meanings specifically of a "kindred spirit" across different cultural contexts would be a valuable exercise.

Of particular interest, is how the concept of kindred spirit connection may be relevant to different professional practice contexts. We suggest there may be value in 
explicitly engaging the concept of kindred spirit (of which love is a part) within a therapy context, for instance. Aiming to establish a kindred spirit connection may be helpful as part of developing a therapeutic alliance. A client could benefit from feeling a sense of bonding or fellowship with the therapist. The concept found in our research within the bonding dimension of "enrichment" seems particularly relevant as it involves validation, affirmation and feeling enabled, healed, nurtured by the other's recognition, admiration and acceptance. For the client, the sense of bonding may help nurture a feeling of being understood and no longer alone. The concept of chemistry being a part of a kindred spirit connection may help to normalize and give a language for the process of erotic transference for both therapist and client.

In groupwork too, kindred spirit phenomenon may be involved in the transformative potential of groups where members take pride in their mutual interest and affirm each other. From the therapist's perspective, the concept of kindred spirit may well help explain the sense of "flowing easiness," "delighting in the other" and the "meeting of minds" (of the bonding and fellowship dimensions) therapists can experience when with certain clients.

Of course, the wider psychotherapy literature acknowledges something of the role of love and eros in therapy as well as the associated taboos. Sleeth (2010, p. 471), for instance, suggests the "love is the healing principle" and the "fundamental dynamic" underlying all effective treatment. He cites Freud's view of "love as a tool of therapy" and "psychoanalysis and as a cure through love." Others have similarly pointed to the healing potential of the loving therapeutic alliance:

The patient comes to therapy for help with a particular problem, but also the patient is bringing as subtext his or her unique version of a universal aim, namely the achievement of love. Correspondingly, the therapist's desire to help improve the patient's life is an unstated but fundamental wish to give love... The reciprocity of loving and being loved in therapy occurs within the wider field of intersubjective relations that constitute the therapeutic experience. (Natterson, 2003, cited in Sleeth, 2010, p. 473)

Thus, there is some recommendation that psychotherapists teach their clients to learn to love and also to open to the therapist's love. On this latter theme, Clarkson (2003, pp. 27-28) cautions therapists about the damaging effects of engaging sexual or emotional affairs with clients, while acknowledging there is a role for love. She notes the impact of our Western world where anomie, despair and meaningless leaves people with a "burning, pervasive, unfulfilled hunger for intimacy" and how therapists are themselves not unaffected. She highlights how we have to "toil in the space within hearts and yet remain outside.” In poetic reverie she asks:

Shall I give you back your love for me in your love for yourself and perhaps even someday another? Shall I wrap it up in pretty rainbows and shiny hallows? Shall I be there, or step back aghast, keeping my hands and my genitals flaccid and dry, or shall I twist our mutuality into what suits both of us like an old-fashioned rope with which to capture your spirit and betray your body or neither - or shall I be there? (p.30) 
In the context of the search for those elusive relational elements which help to ensure the effectiveness of psychotherapy (Norcross, 2002), further research related to kindred spirit connections may be fruitful. In particular, it may prove helpful to examine and explicate the value of the different dimensions as they emerge developmentally or incrementally in a psychotherapeutic context. For instance, fellowship could be seen as a precursor to the development of bonding; chemistry might be worked through over time to be acknowledged as love. The use of the concept of kindred spirit connection may also offer a broader, and more socially acceptable, discourse - beyond talking about "love" - for explaining multiple layers of relational connection.

Finally, academic discourse aside, this research remains dear to our hearts - not least because it has been the occasion for our own kindred spirit connection to flourish. Dwelling with our participants' stories has brought us immense pleasure. These are tales that still bring a smile to our face and tears to our eyes infusing us both with feelings of warmth and love.

We end as we began with a poem:

\section{Hand}

Away from you, I hold hands with the air, your imagined, untouchable hand. Not there, your fingers braid with mine as I walk. Far away in my heart, you start to talk.

I squeeze the air, kicking the auburn leaves, everything suddenly gold. I half believe your hand is holding mine, the way it would if you were here. What do you say

in my heart? I bend my head to listen, then feel your hand reach out and stroke my hair, as real as the wind caressing the fretful trees above. Now I can hear you clearly, speaking of love.

(Carol Ann Duffy, 2005) 


\section{References}

Buber, M. (1958). I and Thou [Trans. R.G. Smith]. New York: Charles Scribner's Sons. (Original work published 1937)

Case, L.J.B. (1839). A personal letter to Sarah Edgarton, October 18, 1839. Manuscript from a collection at Roosevelt University.

Churchill, S.D. (2007). Experiencing the other within the we: Phenomenology with a bonobo. Chapter 5 in L.Embree and T.Nenon (Eds.). Phenomenology 2005 Vol. IV, Selected Essays from North America (pp.147-170), Bucharest: Zeta EBooks.

Clarkson, P. (2003). The therapeutic relationship (2nd ed.). London: Whurr.

Correia, E. (2008) Love is a hell of a job! Some considerations about love and its importance to psychotherapy. Existential Analysis, July 2008. Retrieved from http://findarticles.com/p/articles/mi_6881/is_2_19/ai_n31874750/?tag=content; col1.

Csikszentmihalyi, M.(1990). Flow: The psychology of optimal experience. New York, NY: Harper and Row.

Duffy, C.A. (2006). Rapture. London, UK: Pan Macmillan.

Fehr, B. (1994). Prototype-based assessment of laypeople’s views of love. Personal Relationships, 1(4), 309-331.

Finlay, L. (2006). Dancing between embodied empathy and phenomenological reflection. Indo-Pacific Journal of Phenomenology, 6 (August), 1-11.

Finlay, L. (2008). A dance between the reduction and reflexivity: Explicating the 'phenomenological psychological attitude,' Journal of Phenomenological Psychology, 39, 1-32.

Finlay, L. (2011). Phenomenology for therapists: Researching the lived world. Chichester, West Sussex: Wiley-Blackwell.

Giorgi, A. (Ed.).(1985). Phenomenological and Psychological research. Pittsburgh, PA: Duquesne University Press.

Heidegger, M. (1962). Being and Time (J.Macquarrie and E. Robinson Trans.). Oxford: Blackwell. (Original work published 1927)

Jager, B. (1989). Transformation of the passions: Psychoanalytic and phenomenological perspectives. In: R.S. Valle \& S. Halling (Eds.), Existentialphenomenological perspectives in psychology: Exploring the breadth of human experience (pp.217-232). New York, NY: Plenum Press. 
Kierkegaard, S. (1995). Works of love: Some Christian deliberations in the form of discourses. Chichester, West Sussex, UK: Princeton University Press (Translated from the original in Danish Kjerlighedens gjerninger. Nogle christelige overveielser i talers form, 1847).

Hatfield, E., Bensman, L., \& Rapson, R.L. (2012). A brief history of social scientists' attempts to measure passionate love. Journal of Social and Personal Relationships, 29(2), 143-164.

Hendrick, S.S., \& Hendrick, C. (1993). Lovers as friends. Journal of Social and Personal Relationships, 10, 459-466.

Lee, J. A. (1988). Love-styles. In R. J. Sternberg (Ed.), The psychology of love (pp. 38-67). New Haven, CT: Yale University Press.

Levinas, E. (1969). Totality and infinity (A. Lingis, Trans.). Pittsburgh, PA: Duquesne University Press. (Original work published 1961).

Lewis, C.S. (1960). The four loves. London, UK: Geoffrey Bles.

Maslow, A. (1968). Toward a Psychology of Being (2nd ed.). New York, NY: Van Nostrand Reinhold .

May, R. (1969). Love and will. New York, NY: W.W.Norton.

Merleau-Ponty, M. (1960/1964). Signs (R.C. McCleary Trans.). Evanston, IL: Northwestern University Press.

Murray, S.L., Holmes, J.G., Bellavia, G., Griffin, D.W., \& Dolderman, D. (2002). Kindred spirits? The benefits of egocentrism in close relationships. Journal of Personality and Social Psychology, 82, 563-581.

Natterson, J.M. (2003). Love in psychotherapy. Psychoanalytic Psychology, 20, 509521.

Norcross, J.C. (Ed.). (2002). Psychotherapy relationships that work: Therapists' contributions and responsiveness to patients. New York, NY: Oxford University Press.

Reeves, C.D.C. (2005). Love's confusions. Cambridge, MA: Harvard University Press.

Ringe, A. (1954). Kindred spirits: Bryant and Cole, American Quarterly, 6, 235-237.

Rogers, C. (1980). A way of being. Boston, MA: Houghton Mifflin.

Sartre, J.-P. (1969). Being and nothingness (H. Barnes, Trans.). London, UK: Routledge. (Original work published 1943). 
Sleeth, D.B. (2010). Integral love: The role of love in clinical practice as a rite of passage. Journal of Humanistic Psychology, 50(4), 471-494.

Smith, J.A., Flowers, P., \& Larkin, M. (2009). Interpretative phenomenological analysis: Theory, method and research. Los Angeles, CA: Sage.

Sternberg, R. J. (1986). A triangular theory of love. Psychological Review, 98(2), 119-135.

Sternberg, R.J. (1988). A triangular theory of love. New York, NY: Basic Books.

Taylor, W., and Lasch, C. (1963). Two "kindred spirits": Sorority and family in New England, 1839-1846. New England Quarterly, 36(1), 23-41.

Tessimond, A.S.J. (1972). Not love perhaps. Retrieved from http://www.poemhunter.com/poem/not-love-perhaps/

Todres, L. (2007). Embodied enquiry. Basingstoke: Palgrave Macmillan.

Todres, L., Galvin, K.T., \& Dahlberg, K. (2007). Lifeworld-led healthcare: Revisiting a humanizing philosophy that integrates emerging trends, Medicine, Health Care and Philosophy, 10, 53-63.

Van Manen, M. (1990). Researching lived experience: Human science for an action sensitive pedagogy. New York, NY: State University of New York Press.

Valle, R.S., \& Halling, S. (Eds.). (1989). Existential-phenomenological perspectives in psychology: Exploring the breadth of human experience. New York, NY: Plenum Press.

Vernon, M. (2005). The philosophy of friendship: New York, NY: Palgrave Macmillan.

Wertz, F. (1983). From everyday to psychological description: Analyzing the moments of a qualitative data analysis, Journal of Phenomenological Psychology, 14(2), 197-241. 